\title{
Transformer insulation aging assessment and life prediction based on variety characteristics
}

\author{
Xun Wan ${ }^{1}$, Kunyu Tan²,a, Yun Liu ${ }^{1}$, Huisheng Ye ${ }^{1}$, Shihua Zhao ${ }^{1}$, Ping Peng ${ }^{1}$, \\ Minfang Peng ${ }^{2}$
}

1State Grid Hunan Electric Power Corporation Research Institute,Changsha,China,410007

2Collge of Electrical and Information Engineering, Hunan University, Changsha, China,410082

akunyutan@126.com

Keywords: transformer;life prediction;insulation aging assessment;variety characteristics

Abstract. In order to make the transformer insulation aging assessment and life prediction more reasonable, we established transformer evaluation model based on the operating load, environmental factors, the electrical characteristics of the experiment and oil chromatographic characteristics. Then we applied the evaluation model to the engineering practice and the prediction result is satisfactory.

\section{Introduction}

Power transformer not only shoulders on the responsibility of supply load, it's safe and stable operation is the urgent need to protect [1]. Therefore, key technology and comprehensive preventive measures for transformer fault detection research and application[2], reduce the damage rate and fault tripping rate is meaningful.

At present, domestic and abroad proposed the concept of "life-cycle management" for transformer, to predict its operation risk and reliability[3], thus combining economic management to make effective maintenance and replacement strategy[4], which is the development trend of the current electric power industry. Therefore, grasp the causes of aging and the development of the underlying causes, as a theoretical guidance for the aging state effectively assess[5], reduce accidents and improve transformer especially safe operation of more than 20 years of operation of the transformer[6], the transformer scientific prolong the life of a very important practical significance.

\section{Transformer Insulation Condition Assessment Model}

Introducing the concept of transformer Health Index (HI) is used to characterize the state of the insulation transformer, and its value ranges from 0 to 10 . The following health level index formula based on the principle of aging equipment[7]. Health index calculation formula:

$$
\mathrm{HI}=\mathrm{HI}_{0} \times \mathrm{e}^{\mathrm{B} \times\left(\mathrm{T}_{2}-\mathrm{T}_{1}\right)}
$$

Where, $\mathrm{HI}_{0}$ is the initial index level health equipment, $\mathrm{HI}$ is the ultimate health index of equipment, $\mathrm{B}$ is aging coefficient, $\mathrm{T}_{1}$ is the new equipment $\mathrm{HI}_{0}$ with the corresponding year, normally be year equipment was put into operation.

This article stated of transformer insulation is divided into five levels, namely, excellent, good, general, degradation, serious, state of transformer insulation and the relationship between the health level values range as shown in table 1. 
Table 1 Relationship between health Index value and the insulation condition

\begin{tabular}{|l|l|}
\hline $\begin{array}{l}\text { Health Index } \\
\text { ranges }\end{array}$ & Insulation status description \\
\hline $0.0-1.5$ & $\begin{array}{l}\text { Excellent, Close to the transition state parameters test value or the factory, } \\
\text { Compared with the similar equipment preferences. Can be postponed for repair. }\end{array}$ \\
\hline $1.5-4.0$ & $\begin{array}{l}\text { Good, Far from procedures stipulated by the state parameters note values, there is } \\
\text { no obvious degradation trend. Can repair extension plan. }\end{array}$ \\
\hline $4.0-6.5$ & $\begin{array}{l}\text { General, degradation trend but have not obvious. Should be preferred schedule } \\
\text { maintenance. }\end{array}$ \\
\hline $6.5-8.0$ & $\begin{array}{l}\text { Degradation, degradation trend; Clear difference compared with the similar } \\
\text { equipment. Arrange maintenance as soon as possible. }\end{array}$ \\
\hline $8.0-10.0$ & $\begin{array}{l}\text { Serious, degradation trend is obvious, Has the remarkable difference compared } \\
\text { with the similar equipment. Need immediately arrange maintenance. }\end{array}$ \\
\hline
\end{tabular}

\section{The determination of main health index}

(1)The determination of aging coefficient B

By the formula (1) taking the logarithm on both sides can be obtained:

$$
\mathrm{B}=\frac{\ln \mathrm{HI}-\ln \mathrm{HI}_{0}}{\mathrm{~T}_{2}-\mathrm{T}_{1}}
$$

$\mathrm{T}_{\text {exp }}^{\prime}=\mathrm{T}_{2}-\mathrm{T}_{1}$, based on the expected life of the transformer is designed to run operating years. Hypothesis, when transformer runs $T_{\text {exp }}^{\prime}$ years later, Significant deterioration of their health status, at the end of life, when its health index will reach 6.5 feet, the accident rate is very high, it may soon be broken.

Transformer initial health index $\mathrm{HI}_{0}$ general index to the health of the transformer when put into operation, generally takes as 0.5 .

Conclusion by formula (2) :

$$
\mathrm{B}=\frac{\ln 6.5-\ln 0.5}{\mathrm{~T}_{2}-\mathrm{T}_{1}}=\frac{\ln 6.5 / 0.5}{\mathrm{~T}_{\text {exp }}^{\prime}}
$$

(2) Determining Equipment life expectancy $\mathrm{T}^{\prime}{ }_{\exp }$

Power transformer during the design, it has been basically established its service life. In considering the design life of the equipment[8], in this paper first grasp the situation of the quality of equipment by the user, setting an expected service life $\mathrm{T}_{\exp }$ of the equipment according to manufacturer and model specifications, then use load factor $f_{L}$ and the environment coefficient $f_{E}$ amending them. Means: 


$$
\mathrm{T}_{\exp }^{\prime}=\frac{\mathrm{T}_{\exp }}{\mathrm{f}_{\mathrm{L}} \times \mathrm{f}_{\mathrm{E}}}
$$

(3)The determination of load factor $f_{L}$

Transformer load rate is the ratio of the average load and the transformer rated capacity of transformer operation carried:

$$
\beta=\frac{S_{\text {ave }}}{S_{\text {rat }}}
$$

After a review of literature and comparative standards and reference values given as load factor correspondence table shown in Table 2.

Table 2 Transformer load coefficient table

\begin{tabular}{|l|l|l|l|l|l|}
\hline Transformer load rate(\%) & $0-40$ & $40-60$ & $60-70$ & $70-80$ & $80-150$ \\
\hline Load factor $\left(\mathrm{f}_{\mathrm{L}}\right)$ & 1 & 1.05 & 1.1 & 1.25 & 1.6 \\
\hline
\end{tabular}

(4)Determination of environmental factor $\mathrm{f}_{\mathrm{E}}$

Different regions, different levels of environmental pollution, the average annual temperature, humidity, local contamination levels[9], etc. After a review of literature and comparative standards and reference values such as environmental factors are given in Table 3.

Table 3 Transformer environment coefficient table

\begin{tabular}{|l|l|l|}
\hline Environment level & Factor $\left(\mathrm{f}_{\mathrm{E}}\right)$ & Features \\
\hline 0 & 1 & Clean Air region and no contaminated areas \\
\hline 1 & 1 & $\begin{array}{l}\text { Mild air polluted areas, industrial areas and low population } \\
\text { density areas, off the coast saltern of } 10 \mathrm{~km}-50 \mathrm{~km} \text { area. Salt } \\
\text { density } \leq 0.06 \mathrm{mg} / \mathrm{cm}^{2}\end{array}$ \\
\hline 2 & 1.05 & $\begin{array}{l}\text { Air moderately contaminated areas, light saline areas, off the } \\
\text { coast saltern area } 3 \mathrm{~km}-10 \mathrm{~km}, \text { Salt density } \\
\text { between } 0.06-0.10\left(\mathrm{mg} / \mathrm{cm}^{2}\right)\end{array}$ \\
\hline 3 & 1.15 & $\begin{array}{l}\text { Air pollution is more serious areas, heavy fog and heavy saline } \\
\text { areas, near the coast saltern } 1 \mathrm{~km}-3 \mathrm{~km} \text { area, away from } \\
\text { chemical pollution is more serious contamination source area } \\
\text { of } 300 \mathrm{~m}-1500 \mathrm{~m}, \text { Salt density between } 0.10-0.25\left(\mathrm{mg} / \mathrm{cm}^{2}\right)\end{array}$ \\
\hline 4 & 1.3 & $\begin{array}{l}\text { Particularly serious air pollution in areas within the salt from } \\
\text { the coast } 1 \mathrm{~km}, \text { less than } 300 \mathrm{~m} \text { from chemical pollution source } \\
\text { areas, Salt density between } 0.25-0.35\left(\mathrm{mg} / \mathrm{cm}^{2}\right)\end{array}$ \\
\hline
\end{tabular}

(5)Primary health index $\mathrm{HI}_{\mathrm{m}}$

According to the transformer health index formula:

$\mathrm{HI}_{\mathrm{m}}=\mathrm{HI}_{0} \times \mathrm{e}^{\mathrm{B} \times\left(\mathrm{T}_{2}-\mathrm{T}_{1}\right)}=0.5 \times \mathrm{e}^{\mathrm{B} \times\left(\mathrm{T}_{2}-\mathrm{T}_{1}\right)}$ 


\section{Electrical test characteristics reflecting the health level index}

Selected based on the evaluation of the electrical characteristics are: 1 winding DC resistance unbalance factor ; 2 winding insulation resistance; 3 winding dielectric loss $\operatorname{tg} \delta$. According to these seven test scores of feature amounts using Analytic Hierarchy Process score obtained for each characteristic amount of weight, so using the formula:

$$
H I_{E T}=\sum_{i=1}^{3} \omega i \times F(i)
$$

(1)Winding DC resistance unbalance factor $\mathrm{X}(\%)$ characterize the state of the score $F_{1}$, Its value can be $X=2 \%$, cut-off point for the piecewise function expression is:

$$
F_{1}= \begin{cases}3.02 x & x \in[0,2) \\ 0.99 x+4.06 & x \in[2,6] \\ 10 & x \in(6,+\infty)\end{cases}
$$

(2)Winding insulation resistance $R(M \Omega)$ to characterize the state of the score $F_{2}$, which value can be cut-off point $R_{20}=800 M \Omega$ for the piecewise function, the function expression is:

$$
F_{2}= \begin{cases}-0.0037 R+9.08 & R \in[0,800) \\ -0.0041 R+9.4 & R \in[800,2200) \\ 0 & \mathrm{R} \in[2200,+\infty)\end{cases}
$$

(3)Winding dielectric loss tangent $\operatorname{tg} \delta(\%)$ characterize the state of the score $F_{3}$, which value can be segmented as a function of the demarcation point $\operatorname{tg} \delta=0.8 \%$, the function expression is:

$$
F_{3}= \begin{cases}7.475 t & t \in[0,0.8) \\ 5.2 \mathrm{t}+1.92 & t \in[0.8,1.5] \\ 10 & \mathrm{t} \in(1.5,+\infty)\end{cases}
$$

Obtain electrical test related feature amount of each factor by the Analytic Hierarchy Process score weighting $\omega_{i}(i=1,2,3)$ is: $0.2339,0.4834,0.2827$. Whereby electrical test can be calculated related feature amount index reflects the level of health $H I_{E T}$.

\section{Oil chromatographic tests reflecting the health level index}

Characterization of transformer insulation aging degree in hydrocarbon content, calculate hydrocarbon index and scoring $\mathrm{F}_{\mathrm{C}, \mathrm{H}}$. Considering the differences between the standard, according to $\mathrm{H}_{2}, \mathrm{CH}_{4}, \mathrm{C}_{2} \mathrm{H}_{4}$ three kind of the test results of the gas, the functions can be expressed $\mathrm{F}_{\mathrm{i}}=\mathrm{ax} \mathrm{x}_{\mathrm{i}} \mathrm{b}$ (i $=1,2,3$ means five gas) in the form of a given. 
Table 4 Hydrocarbon gas factor score $\mathrm{F}_{\mathrm{C}, \mathrm{H}}$ calculation table

\begin{tabular}{|c|c|c|c|c|}
\hline gas & $x_{i(\mu L / L)}$ & $a$ & $b$ & $F_{C, O}(i)$ \\
\hline \multirow{5}{*}{$\mathrm{H}_{2}$} & $\leq 30$ & 0 & 0 & \multirow{4}{*}{$a x_{1}+b$} \\
\hline & $30-50$ & 0.1 & -3 & \\
\hline & $50-100$ & 0.06 & 1 & \\
\hline & $100-500$ & 0.0125 & 3.75 & \\
\hline & $>500$ & & & 10 \\
\hline \multirow[t]{4}{*}{$\mathrm{CH}_{4}$} & $\leq 10$ & 0 & 0 & \multirow{3}{*}{$a x_{2}+b$} \\
\hline & $10-15$ & 0.4 & -2 & \\
\hline & $15-125$ & 0.0727 & 0.9 & \\
\hline & $>125$ & & & 10 \\
\hline \multirow[t]{5}{*}{$\mathrm{C}_{2} \mathrm{H}_{4}$} & $\leq 10$ & 0 & 0 & \multirow[t]{4}{*}{$a x_{4}+b$} \\
\hline & $10-30$ & 0.1 & -1 & \\
\hline & $30-50$ & 0.15 & -2.5 & \\
\hline & $50-175$ & 0.04 & 3 & \\
\hline & $>175$ & & & 10 \\
\hline
\end{tabular}

Three gas fraction value can be calculated according to the type hydrocarbon gas dissolved in transformer oil content reflects the health index $\mathrm{HI}_{\mathrm{C}, \mathrm{H}}$ :

$$
H I_{C, H}=\sum_{i=1}^{3} \omega_{i} F_{C, H}(i)
$$

By analytic hierarchy process can get the $\mathrm{H}_{2}, \mathrm{CH}_{4}, \mathrm{C}_{2} \mathrm{H}_{4}$, three gas weights of each factor score $(i=1,2,3)$ are: $0.3725,0.5033,0.1241$. Which can be calculated transformer oil chromatography test reflect the health level index $H I_{C . H}$.

\section{Determination for final comprehensive health index}

Comprehensive health index is based on the main health index, electrical test health index, oil chromatographic test health index three points index $\left(\mathrm{HI}_{\mathrm{m}} 、 H I_{E T} 、 \mathrm{HI}_{\mathrm{C}, \mathrm{H}}\right)$ and the combination of their respective weight calculation, calculation expression is as follows:

$$
H I_{c o m}=\sum_{i=1}^{3} \omega_{i} H I_{(i)}
$$

Considering a large number of experimental results and operating experience, combined with the hierarchical analysis method, three points and health index weights $\omega_{i}(i=1,2,3)$, respectively: $0.6324 、 0.1423 、 0.2253$.

\section{Testing the evaluation model}

In order to verify the correctness of the model proposed in this paper, we collected historical test data of $500 \mathrm{kv}$ main transformer 2\# in Wuqiangxi Hydropower station. Hereinafter analysis and calculation for the main transformer $2 \#$ 


\section{1. main transformer status 2 \#}

Running main transformer 2\# of Wuqiangxi Hydropower station, voltage level of 500kV, model specifications for ssp-300000/500, the design life of 40 years, put into operation date of September 25, 2013, the average annual load was 0.7 , the relevant test data are shown in table 7 .

Table 7 Test Data

\begin{tabular}{|c|c|c|c|}
\hline \multirow[b]{2}{*}{ Name } & \multicolumn{3}{|c|}{ Electrical test data } \\
\hline & $\begin{array}{l}\text { Winding three-phase } \\
\text { unbalance factor }(\%)\end{array}$ & $\begin{array}{c}\text { Winding } \\
\text { insulation } \\
\text { resistance }(M \Omega)\end{array}$ & $\begin{array}{l}\text { Winding dielectric loss } \\
\text { factor }(\%)\end{array}$ \\
\hline Value & 0.52 & 38500 & 0.5 \\
\hline \multirow{2}{*}{ Name } & \multicolumn{3}{|c|}{ Oil chromatographic test data $(\mathrm{uL} / \mathrm{L})$} \\
\hline & $\mathrm{H}_{2}$ & $\mathrm{CH}_{4}$ & $\mathrm{C}_{2} \mathrm{H}_{4}$ \\
\hline Value & 34.91 & 3.81 & 0.31 \\
\hline
\end{tabular}

(1)Aging the main health index

By type (2) on both sides of the exponential available:

$$
\mathrm{B}=\frac{\ln 6.5-\ln 0.5}{\mathrm{~T}_{2}-\mathrm{T}_{1}}=\frac{\ln 6.5 / 0.5}{\mathrm{~T}_{\exp }^{\prime}}
$$

Since 2 \# main transformer design life of 40 years, equipment in good operating environment, load rate 0.7 , the table 2 and table 3 shows that load factor $f_{L}=1.25$, the environmental factor $f_{E}=1$.

Into the above equation can be obtained: equipment life expectancy is 32 years, the aging factor $B=0.0802$.Then, according to the type (1), After $\left(T_{2}-T_{1}=2.5\right)$ years of transformer was put into operation ,the main health index:

$$
H I_{m}=H I_{0} \times e^{B \times\left(T_{2}-T_{1}\right)}=0.5 \times e^{B \times\left(T_{2}-T_{1}\right)}=0.611
$$

(2)Electrical test health index

According to the characters of electrical test, State score $F_{1}=1.57 、 F_{2}=0 、 F_{3}=3.7375$.

$$
H I_{E T}=\sum_{i=1}^{3} w_{i} \times F_{i}=1.424
$$

(3) Oil chromatographic test health index

According to table 4, can score hydrocarbon gases dissolved in transformer oil is calculated, and combining the weight values, the calculation of oil chromatographic test health index:

$$
H I_{C, H}=\sum_{i=1}^{3} w_{i} F(\mathrm{i})=0.491
$$


(4) Finally comprehensive health index

The weight values of the table, to calculate comprehensive health index of transformer:

$$
H I_{\text {com }}=\sum_{i=1}^{3} \omega_{i} H I_{(i)}=0.699
$$

Final assessment of the health index $H I=0.699$.Described as: Excellent. Based on the current transformer information, operation and test information, from the above model assessment results, the short time transformer was put into operation, running environment is good, good insulation aging state, this is the actual situation of the main transformer \# 2.

\section{Conclusion}

In this paper, considering a variety of characteristics can be extracted, reasonable transformer condition assessment model is established. And the correctness of the model is verified by examples, results have important implications for the development of the transformer condition assessment policy.

\section{Acknowledgements}

This work is supported by National Natural Science Foundation of China under Grant No.61472128 and 61173108, and Hunan Provincial Natural Science Foundation of China No.14JJ2150.

\section{References}

[1]. Kassi, K.S., et al., Analysis of Aged Oil on the Cooling of Power Transformers from Computational Fluid Dynamics and Experimental Measurements. JOURNAL OF APPLIED FLUID MECHANICS, 2016. 9(2): p. 235-243.

[2]. Goyal, A., et al., Asset health management using predictive and prescriptive analytics for the electric power grid. IBM JOURNAL OF RESEARCH AND DEVELOPMENT, 2016. 60(41).

[3]. Gao, J., et al., Condition Diagnosis of Transformer Oil-paper Insulation Using Dielectric Response Fingerprint Characteristics. IEEE TRANSACTIONS ON DIELECTRICS AND ELECTRICAL INSULATION, 2016. 23(2): p. 1207-1218.

[4]. Mildemberger, L., et al., Correlation between stabilizer consumption and degree of polymerization of thermally upgraded paper aged in insulating natural ester and insulating mineral oil. POLIMEROS-CIENCIA E TECNOLOGIA, 2016. 26(1): p. 61-65.

[5]. Aleksandrovic, S. and M. Jovic, Economic and technical aspects of transformer operation. ENERGY SOURCES PART B-ECONOMICS PLANNING AND POLICY, 2016. 11(1): p. 26-31.

[6]. Wang, Z., et al., Effects of aging on the structural, mechanical, and thermal properties of the silicone rubber current transformer insulation bushing for a $500 \mathrm{kV}$ substation. SPRINGERPLUS, 2016. 5(790).

[7]. Jin, M. and J. Pan, Effects of Insulation Paper Ageing on the Vibration Characteristics of a Transformer Winding Disk. IEEE TRANSACTIONS ON DIELECTRICS AND ELECTRICAL INSULATION, 2015. 22(6): p. 3560-3566.

[8]. Tang, C., et al., Experimental Analyses and Molecular Simulation of the Thermal Aging of Transformer Insulation Paper. IEEE TRANSACTIONS ON DIELECTRICS AND ELECTRICAL INSULATION, 2015. 22(6): p. 3608-3616. 
[9]. Zubiate, P., et al., Fabrication of Optical Fiber Sensors for Measuring Ageing Transformer Oil in Wavelength. IEEE SENSORS JOURNAL, 2016. 16(12): p. 4798-4802. 